\title{
Microsatellite instability in colorectal cancer and association with thymidylate synthase and dihydropyrimidine dehydrogenase expression
}

\author{
Søren A Jensen*1, Ben Vainer ${ }^{2}$, Mogens Kruhøffer ${ }^{3}$ and Jens B Sørensen ${ }^{1}$
}

Address: ${ }^{1}$ Department of Oncology, Rigshospitalet, Copenhagen University Hospital, Copenhagen, Denmark, ${ }^{2}$ Department of Pathology, Rigshospitalet, Copenhagen University Hospital, Copenhagen, Denmark and ${ }^{3}$ Department of Clinical biochemistry, Skejby, Aarhus University Hospital, Aarhus, Denmark

Email: Søren A Jensen* - soren.a.jensen@mail.tele.dk; Ben Vainer - ben.vainer@rh.regionh.dk; Mogens Kruhøffer - MKR@KI.AU.DK; Jens B Sørensen - jens.benn.soerensen@rh.regionh.dk

* Corresponding author

Published: 20 January 2009

BMC Cancer 2009, 9:25 doi:10.1 186/147|-2407-9-25
Received: 31 July 2008

Accepted: 20 January 2009

This article is available from: http://www.biomedcentral.com/I47I-2407/9/25

(C) 2009 Jensen et al; licensee BioMed Central Ltd.

This is an Open Access article distributed under the terms of the Creative Commons Attribution License (http://creativecommons.org/licenses/by/2.0), which permits unrestricted use, distribution, and reproduction in any medium, provided the original work is properly cited.

\begin{abstract}
Background: Microsatellite instability (MSI) refers to mutations in short motifs of tandemly repeated nucleotides resulting from replication errors and deficient mismatch repair (MMR). Colorectal cancer with MSI has characteristic biology and chemosensitivity, however the molecular basis remains unclarified. The association of MSI and MMR status with outcome and with thymidylate synthase (TS) and dihydropyrimidine dehydrogenase (DPD) expression in colorectal cancer were evaluated.
\end{abstract}

Methods: MSI in five reference loci, MMR enzymes (hMSH2, hMSH6, hMLHI and hPMS2), thymidylate synthase (TS) and dihydropyrimidine dehydrogenase (DPD) expression were assessed in paraffin embedded tumor specimens, and associated with outcome in 340 consecutive patients completely resected for colorectal cancer stages II-IV and subsequently receiving adjuvant 5fluorouracil therapy.

Results: MSI was found in $43(13.8 \%)$ tumors. Absence of repair protein expression was assessed in $52(17.0 \%)$ tumors, which had primarily lost hMLHI in 39 (I2.7\%), hMSH2 in $5(1.6 \%)$, and hMSH6 in 8 (2.6\%) tumors. In multivariate analysis MSI (instable) compared to MSS (stable) tumors were significantly associated with lower risk of recurrence (hazard ratio $(\mathrm{HR})=0.3 ; 95 \% \mathrm{Cl}: 0.2-$ $0.7 ; \mathrm{P}=0.0007)$ and death $(\mathrm{HR}=0.4 ; 95 \% \mathrm{Cl}: 0.2-0.9 ; \mathrm{P}=0.02)$ independently of the TS and DPD expressions. A direct relationship between MSI and TS intensity $(P=0.00 \mathrm{I})$ was found, while there was no significant association with DPD intensity $(P=0.1)$.

Conclusion: The favourable outcome of MSI colorectal carcinomas is ascribed mainly to the tumor biology and to a lesser extent to antitumor response to 5 -fluorouracil therapy. There is no evidence that differential TS or DPD expression may account for these outcome characteristics. 


\section{Background}

Colorectal cancer is the fourth most common malignant tumor in Western Europe and Northern America affecting $7 \%$ of the population and ranks as the second leading cause of cancer-related mortality [1].

The majority of colorectal cancers display aneuploidy appearing as chromosomal anomalies, whereas the remainder that constitutes $15-20 \%$ of these cancers is characterized by microsatellite instability (MSI) [2-6].

Microsatellites are DNA sequences in which a short motif of 1-5 nucleotides are tandemly repeated ten to hundred times. Microsatellites are prone to mutation during replication due to transient split of the two helical strands and slippage of the DNA polymerase complex at reannealing, which generate an insertion or deletion loop depending on slippage direction. Unless such mismatch is corrected, the loss or gain of repeated units on the daughter strand results in length variation termed microsatellite instability (MSI) [7].

The mismatch repair (MMR) is performed by the proteins hMSH2 heterodimerized with hMSH6 for recognition of a loop of few mismatched extrahelical nucleotides. Upon assemblage this complex interact with another heterodimeric complex, composed of hMLH1 and hPMS2 [8].

Deficient MMR that arise in sporadic colorectal cancer is nearly always due to an epigenetic biallelic hypermethylation of the hMLH1 gene promoter. In addition, MMR deficiency may result from genetic disorders, caused by an inherited germ-line mutation of one allele followed by an acquired alteration of the wild-type allele leading to inactivation of one of the three main MMR genes (MLH1, MSH2, and MSH6) [7].

While most of the half million microsatellite sequences scattered in the human genome are located within untranslated regions, in which MSI is assumed to be without significance to expression, a number of genes involved in mitosis and apoptosis carry microsatellites in their encoding regions [9]. MMR deficiency may promote malignant transformation as it allows accumulation of microsatellite insertion/deletion mutations, leading to MSI-driven inactivation of genes having key regulatory functions [10]. Besides being pathogenetic to malignant transformation MSI also characterises a subset of colorectal cancers with characteristic biology and chemosensitivity. Accordingly, in pooled analysis of patients with local and advanced disease high-frequency MSI (MSI-H) was associated with a favorable prognosis compared to microsatellite stable/low-frequency MSI (MSS/MSI-L) inde- pendently of chemotherapy [11]. Moreover, in the context of 5-fluorouracil therapy patients with MSS/MSI-L tumors had improved overall survival, whereas no similar benefit in outcome pertained to MSI-H tumors $[2,12]$.

Various features of MMR deficient cancer cells as tolerance to accumulate 5-fluorouracil adducts and conspicuous lymfocytic infiltration in tumors have been put forward to account for the opposing trends of relative resistance of chemotherapeutic interventions, against the background of a favourable natural history [13].

Whether microsatellite instability deregulates genes related to tumor growth and response to 5-fluorouracil therapy, however, has not been clarified. Two such biomarkers thymidylate synthase (TS) [14-18] and dihydropyrimidine dehydrogenase (DPD) [19] play key roles for response to 5-fluorouracil therapy of colorectal cancer. The main mode of action is through irreversible inhibition of TS, whereas the major part of an administered 5fluorouracil dose is catabolised by DPD. In addition, these enzymes may be considered prognostic for the outcome of colorectal cancer independently of chemotherapy as they regulate tumor pyrimidine homeostasis by catalyzing synthesis and degradation, respectively [14-22].

This retrospective study aimed to evaluate the association of MSI and MMR deficiency with outcome and with thymidylate synthase (TS) and dihydropyrimidine dehydrogenase (DPD) expression in tumors from 340 consecutive patients who were completely resected for colorectal cancer stage II-IV and subsequently received adjuvant 5FU treatment.

\section{Methods \\ Patients and chemotherapy}

Consecutive patients completely resected for colon or rectal carcinomas stages II-IV, who received adjuvant chemotherapy at Department of Oncology, Rigshospitalet, Copenhagen University Hospital in the period February 1996 to December 2003 were included.

The adjuvant treatment was according to the Mayo regimen (Mayo Clinic, Rochester, $\mathrm{MN}$ ), including bolus infusion of 5-fluorouracil $\left(425 \mathrm{mg} / \mathrm{m}^{2}\right)$ and isovorin $(10 \mathrm{mg} /$ $\mathrm{m}^{2}$ ) for 5 days, repeated every 4 weeks, for 6 courses. Data on clinical and pathological characteristics and chemotherapy were obtained from surgical, pathological and oncological records. Recurrence and survival data were followed-up September 2007 (censoring date) using databases on hospital admission and the National Central Registry on death recording. The local research ethics committee has approved this study and for the samples to be used in research (KF01-201/03, 01-286965). 


\section{Tumor samples}

Archival tumor samples were collected from the pathological departments serving the surgical departments that referred cancer patients to Department of Oncology, Rigshospitalet. Out of 352 tumor specimens requested, 340 tumor specimens were accessible and contained representative tumor tissue, that were evaluated as to the type of carcinoma, degree of differentiation, perineural tumour growth and vascular invasion using one section from each block stained by routine heamatoxylin and eosin (HE) staining.

\section{Microsatellite analysis}

Guided by microscopic examination of the HE stained slide, areas with at least 50\% tumor cells present were grossly dissected from four $10 \mu \mathrm{m}$ sections mounted onto glass slides, and DNA was isolated and prepared for microsatellite analysis. Microsatellite instability was determined in tumor DNA without the need for matching normal tissue DNA [23] using the highly specific panel of five quasimonomorphic mononucleotide repeats NR-21, NR-22, NR-24, BAT-25, and BAT-26 $[23,24]$ in a pentaplex polymerase chain reaction as previously described [25]. For the purpose of prognostic evaluation microsatellite status was categorized as MSS (stable) versus MSI (instable) whether having instability in no (0) or more $(\geq 1)$ markers, respectively.

\section{Immunohistochemistry}

From the tissue specimens $2 \mathrm{~mm}$ cylinders were punched out and collected in microarray paraffin blocks each containing 40 samples. Tissue from normal kidney, liver and lymph node was included in the tissue arrays serving as reading frame and controls.

Sections of $4 \mu \mathrm{m}$ were cut from the arrays and deparaffinized in xylene and rehydrated. Antigen retrieval was performed by immersing the slides in a $10 \mathrm{mM}$ citrate buffer (pH 6 for hMLH1 and pH 7 for hMSH2, hMSH6, and hPMS2), and heating them in a microwave oven for 30 $\min$ at $95^{\circ} \mathrm{C}$. Endogenous peroxidase was quenched by incubation of samples with $0.3 \%$ hydrogen peroxide in methanol. After washing in phosphate buffered saline (PBS), the sections were placed in $20 \%$ normal goat serum in PBS for 20 minutes to reduce non-specific staining. Sections were then incubated with monoclonal antibodies raised against hMLH1 (clone G168-15, 1:50 dilution; BD PharMingen, San Diego, CA), hMSH2 (clone NA27, 1:30 dilution; Oncogene Research Products, Darmstadt, Germany), hMSH6 (clone 44, 1:200 dilution; BD Transduction Laboratories), or PMS2 (clone 37, 1:250 dilution; BD PharMingen) for 1 hour at room temperature. TS and DPD stainings were done as previously described [20]. Subsequently, visualization was performed using the
DAKO EnVision Duallink technique (DAKO, Glostrup, Denmark) according to the manufacturer's instruction and using diaminobenzidine as a chromogen.

Immunohistochemical staining of TS and DPD was assessed semi-quantitatively. TS staining intensity was scored (0-3) using the scale 0 : no staining, 1 : weak staining, 2: moderate staining, and 3: intense staining. Tumour cells with the highest DPD intensity were evaluated and assigned a score (0-3) using the scale 0: no staining, 1 : faint ambiguous staining, 2: partly staining of cell membranes, 3: staining of cell membranes and cytoplasm. MMR proteins were scored as either no or positive staining. During loss of expression of a MMR protein the heterodimer may degrade too resulting in distinct patterns of absence of nuclear staining for each of the proteins hMLH1 (hMLH1, hPMS2), hMSH2 (hMSH2, hMSH6), and hMSH6 (hMSH6). Definite nuclear staining of adjacent non-tumor cells (e.g. lymphocytes, fibroblasts and endothelial cells) in the tissue array served as an internal positive control. Negative controls were performed by omitting the primary antibodies and by application of an isotype-matched non-reactive immunoglobulin in each staining run. Tissue specimens were analysed blinded to all other analyses and clinical information.

\section{Statistics}

The relationships between tumor microsatellite status and clinicopathologic features were analyzed using Chi-square test or Mann-Whitney U-test, as appropriate. Survival time was calculated from the time point of the complete resection of the tumor. The outcome variables were recurrence free survival (RFS), defined as time to relapse of primary disease or death, whichever occurred first, and death from any cause for overall survival (OS). Distributions of RFS and OS were displayed using Kaplan-Meier methodology, and univariate survival distributions were compared using the log-rank test. Cox proportional hazard modeling was used to evaluate the association of RFS and OS with clinicopathological characteristics and MSI and MMR status. All candidate prognostic variables were initially entered into the model, and non-significant $(\mathrm{P}>0.1)$ variables were subsequently rejected (step-down variable selection). Graphical methods were used to ascertain underlying model assumptions as proportional hazards. The interaction between TS or DPD expression and microsatellite status with outcome was evaluated in a Cox model. Multivariate logistic regression was used to test for the association of MSI status with the independent variables TS, DPD and clinicopathological characteristics. Kappa statistics was performed for comparison of MSI and MMR analyses. Two-sided $\mathrm{P}<0.05$ was considered statistically significant. Statistics was performed with Statistica software (Statsoft Inc. Tulsa, OK, USA). 


\section{Results \\ Clinicopathology, microsatellite instability and mismatch repair protein expression}

Microsatellite status was assessed in 311 (92\%) of 340 tumors. In the remainders analyses failed for technical reasons partly because of DNA degradation in tumor necrosis. In the microsatellite study sample 43 (13.8\%) tumors had MSI. In the MSI subset the frequencies of mutated microsatellite loci were for NR-21 41 (95.3\%), NR-22 38 (88.4\%), NR-24 28 (65.1\%), BAT-25 42 $(97.7 \%)$, and BAT-26 $42(97.7 \%)$, respectively. MSI tumors had instability in at least three and in most cases four markers, while MSS tumors had none.

Expression of mismatch repair proteins hMLH, hMSH2, hMSH6 and hPMS2 was assessed in 306 (90\%) tumor specimens using immunohistochemistry. The analysis failed in the remaining archival samples mainly because of loss of tissue cylinders during sectioning of arrays. Absence of repair protein expression was stated in 52 $(17.0 \%)$ tumors. The coincidental absence of nuclear staining of a repair protein and its heterodimer indicated that loss of expression had primarily occurred for hMLH1 in $39(12.7 \%), \mathrm{hMSH} 2$ in $5(1.6 \%)$, and for hMSH6 in 8 $(2.6 \%)$ tumors.

Clinical and pathological characteristics according to microsatellite status are shown in Table 1. MSI tumors had a bimodal age distribution with significantly more elderly patients $(\mathrm{P}=0.02)$ and few younger patients. Tumors with MSI were poorly differentiated $(P=0.001)$. MSI tumors were mainly located proximally to the splenic flexure in ascending and transverse colon $(P=0.001)$, and had minor risk of ileus at resection $(P=0.01)$. There were no statistically significant differences $(\mathrm{P}>0.05)$ according to microsatellite status regarding gender, stage, vascular tumor invasion, perineural tumor invasion, or tumors complicated by perforation.

\section{Microsatellite instability and mismatch repair protein expression}

Compared to MSI status as the standard the immunohistochemical analyses of MMR proteins had a sensitivity of 0.95 , a specificity of 0.93 , a positive predictive value of 0.67 , and a negative predictive value of 0.99 , that resulted in an overall accuracy of 0.93. Correspondence between MSI readings and immunohistochemical analyses led to a Kappa value of 0.75 .

\section{Disease recurrence and survival}

During follow up (median 6.1 years; range 4.1-11.3 years) 121 patients (36\%) had documented recurrent disease and 153 patients (45\%) have expired. Median overall survival was 9.5 years, and the 5 year survival rate was $62 \%$.

\section{Microsatellite instability, mismatch repair protein expression and outcome}

In univariate analyses of outcome according to MMR status stratified by disease stage (Table 2), patients having MMR deficient compared to MMR proficient tumors had significantly lower risk of recurrence $(\mathrm{HR}=0.5 ; 95 \% \mathrm{CI}$ : $0.3-0.9 ; \mathrm{P}=0.006$ ) (Figure $1 \mathrm{a})$ and death $(\mathrm{HR}=0.6 ; 95 \%$ CI: $0.3-1.0 ; \mathrm{P}=0.04$ ) (Figure $1 \mathrm{~b}$ ). In multivariate analysis of outcome MMR deficient compared to MMR proficient tumors were significantly associated with lower risk of recurrence $(\mathrm{HR}=0.4 ; 95 \% \mathrm{CI}: 0.3-0.8 \mathrm{P}=0.003)$ and death $(\mathrm{HR}=0.5 ; 95 \% \mathrm{CI}: 0.3-0.9 ; \mathrm{P}=0.02)$, when controlling for the influence of other independent predictors of recurrence; disease stage $(\mathrm{P}=0.001)$, perineural invasion $(\mathrm{P}=0.05)$, and ileus $(\mathrm{P}=0.0002)$.

Similarly, in univariate analyses of outcome according to microsatellite status stratified by disease stage (Table 2), patients with MSI compared to MSS tumors had significantly lower risk of recurrence ( $\mathrm{HR}=0.4 ; 95 \% \mathrm{CI}: 0.2-0.7$; $\mathrm{P}=0.002$ ) (Figure $2 \mathrm{a}$ ) and death (HR $=0.5 ; 95 \% \mathrm{CI}: 0.2-$ $0.9 ; \mathrm{P}=0.02$ ) (Figure $2 \mathrm{~b}$ ). Also in multivariate analysis of outcome MSI compared to MSS tumor patients had significantly lower risk of recurrence ( $\mathrm{HR}=0.3 ; 95 \% \mathrm{CI}$ : $0.2-$ $0.7 ; \mathrm{P}=0.0007)$ (Figure $3 \mathrm{a})$ and death $(\mathrm{HR}=0.4 ; 95 \% \mathrm{CI}$ : $0.2-0.9 ; \mathrm{P}=0.02$ ) (Figure $3 \mathrm{~b}$ ) adjusted for the prognostic influence of disease stage $(\mathrm{P}=0.0001)$, vascular invasion $(P=0.02)$, perineural invasion $(P=0.05)$, and ileus $(P=$ $0.0002)$.

\section{Microsatellite instability and association with TS and DPD expression}

The distribution of biomarkers according to microsatellite status (Table 1) indicated a direct relationship between MSI and increasing TS staining intensity $(P=0.001)$, while there was no evidence of an association with DPD staining intensity $(P=0.1)$. Similar results applied to the relationship between MMR status and expression of TS (P $=0.0001)$ and DPD $(P=0.3)$.

Logistic regression testing relating MSI status and clinicopathological variables to the value of biomarkers as dependent variables revealed statistically significant association with increasing TS expression (global $\mathrm{P}=0.0001$ ), and non-significant association with DPD expression $(\mathrm{P}=$ $0.4)$.

Tests for interaction between biomarker expression and MSI status to predict outcome, using Cox analysis, were statistically significant for TS for recurrence $(P=0.002)$ and overall survival $(P=0.02)$, and non significant for DPD for recurrence $(\mathrm{P}=0.5)$ and overall survival $(\mathrm{P}=$ 0.9). With adjustment for multiple comparisons of four interactions considered, involving two biomarkers and two outcomes, the test values for TS were statistically sig- 
Table I: Clinicopathological characteristics and tumor biomarker score according to microsatellite status.

\begin{tabular}{|c|c|c|c|c|c|}
\hline & \multicolumn{2}{|c|}{$\begin{array}{c}M S I^{*} \\
n=43\end{array}$} & \multicolumn{2}{|c|}{$\begin{array}{c}\text { MSS* } \\
\mathrm{n}=268\end{array}$} & \multirow[t]{2}{*}{$P$} \\
\hline & No. & $(\%)$ & No. & (\%) & \\
\hline \multicolumn{6}{|l|}{ Gender } \\
\hline Male & 21 & $(49)$ & 138 & $(5 \mathrm{I})$ & 0.9 \\
\hline Female & 22 & (5I) & 130 & (49) & \\
\hline \multicolumn{6}{|l|}{ Age } \\
\hline$<70$ & 28 & $(65)$ & 217 & $(8 I)$ & 0.02 \\
\hline$\geq 70$ & 15 & (35) & 51 & (19) & \\
\hline \multicolumn{6}{|l|}{ Tumor site } \\
\hline Proximal colon & 36 & $(84)$ & 68 & $(25)$ & 0.001 \\
\hline Distal colon & 6 & (14) & 145 & $(54)$ & \\
\hline Rectum & I & (2) & 55 & $(2 I)$ & \\
\hline \multicolumn{6}{|l|}{ Stage } \\
\hline II & 6 & $(14)$ & 26 & $(10)$ & 0.4 \\
\hline III & 34 & (79) & 210 & (78) & \\
\hline IV & 3 & (7) & 32 & $(12)$ & \\
\hline \multicolumn{6}{|c|}{ Differentiation grade (WHO) } \\
\hline Well & 5 & $(12)$ & 88 & (33) & 0.001 \\
\hline Intermediate & 7 & $(16)$ & $12 \mid$ & $(45)$ & \\
\hline Poor & 31 & $(72)$ & 59 & $(22)$ & \\
\hline \multicolumn{6}{|c|}{ Perineural tumor invasion } \\
\hline+ & 5 & $(12)$ & 53 & $(20)$ & 0.5 \\
\hline- & 19 & (44) & 137 & $(5 \mathrm{I})$ & \\
\hline not assessed & 19 & (44) & 78 & (29) & \\
\hline \multicolumn{6}{|c|}{ Vascular tumor invasion } \\
\hline Vo & 18 & $(42)$ & 142 & $(53)$ & 0.8 \\
\hline VI & 8 & (19) & 58 & $(22)$ & \\
\hline$V_{x}$ & 17 & (39) & 68 & $(25)$ & \\
\hline \multicolumn{6}{|c|}{ Intestinal perforation at resection } \\
\hline yes & 2 & (5) & 29 & (II) & 0.2 \\
\hline no & 41 & $(95)$ & 239 & (89) & \\
\hline \multicolumn{6}{|c|}{ Bowel obstruction before resection } \\
\hline yes & I & $(2)$ & 44 & $(16)$ & 0.01 \\
\hline no & 42 & (98) & 224 & $(84)$ & \\
\hline \multicolumn{6}{|c|}{ Thymidylate synthase level } \\
\hline Low & 12 & $(28)$ & 218 & $(8 I)$ & 0.001 \\
\hline High & 30 & $(70)$ & 47 & $(18)$ & \\
\hline not assessed & I & $(2)$ & 3 & (I) & \\
\hline \multicolumn{6}{|c|}{ Dihydropyrimidine dehydrogenase level } \\
\hline Low & 21 & $(49)$ & 163 & $(6 I)$ & 0.1 \\
\hline High & 21 & $(49)$ & 97 & $(36)$ & \\
\hline not assessed & I & (2) & 8 & (3) & \\
\hline
\end{tabular}

*instable (MSI) or stable (MSS) microsatellites

nificant for recurrence $(P=0.01)$ and non significant for overall survival $(\mathrm{P}=0.1)$.

\section{Discussion}

In keeping with previous reports $[2-4,6]$ and a meta-analysis [11] this study found a favourable outcome associated with MSI as compared to MSS of resected colorectal carcinomas stage II-IV in the adjuvant setting. These findings were based on uniform criteria for categorization of microsatellite instability using the NCI recommended reference panel of five loci [24]. In addition, characterization of mismatch repair competency by assessing expression of four main mismatch repair proteins corroborated these results. Others reported no prognostic significance of microsatellite instability in this setting, based on various criteria for microsatellite status [5,26-29].

Initial investigations into the predictive role of microsatellite instability showed similar improvement in outcome from adjuvant 5-fluorouracil therapy irrespective of microsatellite status of the resected adenocarcinomas $[28,30]$. Inadvertantly biased treatment groups for comparison 
Table 2: Outcome according to microsatellite instability and mismatch repair deficiency stratified by disease stage.

\begin{tabular}{|c|c|c|c|c|c|c|c|c|c|}
\hline & \multirow[b]{2}{*}{ No. } & \multicolumn{4}{|c|}{ Recurrence free survival } & \multicolumn{4}{|c|}{ Overall survival } \\
\hline & & Events & Hazard & atio $(95 \% \mathrm{Cl})$ & $P$ & Events & Hazard & atio $(95 \% \mathrm{Cl})$ & $P$ \\
\hline \multicolumn{10}{|c|}{ Microsatellite status* } \\
\hline All stages & 311 & 113 & 0.4 & $0.2-0.7$ & 0.002 & 138 & 0.5 & $0.2-0.9$ & 0.02 \\
\hline II & 32 & 8 & - & - & - & 13 & - & - & - \\
\hline III & 244 & 81 & 0.5 & $0.3-0.9$ & 0.04 & 101 & 0.6 & $0.3-1.2$ & 0.2 \\
\hline IV & 35 & 24 & - & - & - & 24 & - & - & - \\
\hline \multicolumn{10}{|c|}{ Mismatch repair competence* } \\
\hline All stages & 306 & 149 & 0.5 & $0.3-0.9$ & 0.006 & 132 & 0.6 & $0.3-1.0$ & 0.04 \\
\hline II & 36 & 14 & - & - & - & 13 & - & - & - \\
\hline III & 241 & 112 & 0.6 & $0.4-1.0$ & 0.04 & 100 & 0.7 & $0.4-1.2$ & 0.2 \\
\hline IV & 29 & 23 & - & - & - & 19 & - & - & - \\
\hline
\end{tabular}

*hazard ratios for instable (MSI) relative to stable (MSS) microsatellites, and mismatch repair deficient relative to proficient tumors.

may have accounted for this conclusion. In later reports improved outcome from adjuvant 5 -fluorouracil in terms of reduced recurrence rate and better overall survival related to patients with microsatellite stable tumors only $[2,5,12,29,31-33]$, whereas the subset having MSI cancers gained no similar beneficial effect from chemotherapy [11]. Hence the prevailing evidence suggests that 5-fluorouracil therapy should not be given to patients with MSI colorectal cancer.

On these premises the outcome according to microsatellite status in the present study can therefore be ascribed mainly to the biology of MSI colorectal cancer and to a lesser extent to antitumor response to 5 -fluorouracil therapy. Other clinicopathological features of the MSI carcinomas may contribute to the better prognosis. Hence the minor risk of bowel obstruction associated with right sided tumors is an independent favourable prognostic variable. Moreover the generally lower staging at diagnosis is taken to indicate minor propensity of MSI tumors to metastasize $[11,31,34,35]$. Possibly the decreasing frequency of MSI by stage was not as evident in this cohort because of selection. According to the current treatment algorithm most stage II cancers are not referred for adjuvant chemotherapy unless they have additional poor prognostic factors.

In multivariate analysis the outcome of MSI tumor patients was independent of the TS and DPD levels, suggesting that differential expression of these enzymes could not account for the favourable natural history nor the resistance to chemotherapy $[2,5,12,29,31-33]$.

The major part of an administered dose of 5-fluorouracil is catabolized by dihydropyrimidine dehydrogenase (DPD) into 5,6-dihydrofluorouracil, before it can be converted to the active metabolite fluoro-2'-deoxyuridinemonophosphate that irreversibly inhibits thymidylate synthase. Also the intracellular conversion to 5-fluorouridine and 5-fluoro-2'-deoxyuridine and corresponding phosphates for incorporation into RNA and DNA, respectively, have cytotoxic effect [13]. The similar magnitude of DPD expression regardless of tumor microsatellite status is consistent with MMR deficient cells accumulating 5fluorouracil adducts in DNA [13], which is possibly tolerated due to inability to recognise adducts and to initiate apoptosis.

The correlation between high TS expression and microsatellite instability noticed in this and other studies $[36,37]$ should be interpreted cautiously, as it may not explain prognostic and chemotherapeutic response characteristics of MSI and MMR deficient tumors. Accordingly high TS expression has generally been associated with early disease recurrence independently of chemotherapy [14$18,21]$, while also being related to improved outcome from adjuvant 5-fluorouracil treatment [14-19]. On the other hand, low TS expression has been related to low spontaneous recurrence rate [14-18,21], while indicating relative 5-fluorouracil resistance as well [14-19].

Unlike previous reports $[5,38]$ the potential interaction between TS expression and microsatellite status with disease recurrence was based on a marginal direct relationship between TS level and outcome for patient with MSI tumors, which did not apply to the MSS subset. The low metastatic capacity $[11,31,34,35]$ and high apoptotic index [39] of MSI tumors may counterbalance metabolic features otherwise linked to poor prognosis [14-18,21].

Earlier reports on the relationship between TS intensity and microsatellite instability have been conflicting [5,36$38,40-44]$ arguing either for a direct correlation $[36,37]$ or no such association $[5,38,41,42]$. The discrepancy may partly relate to lack of consistency in criteria defining microsatellite instability, as some studies were based on sin- 

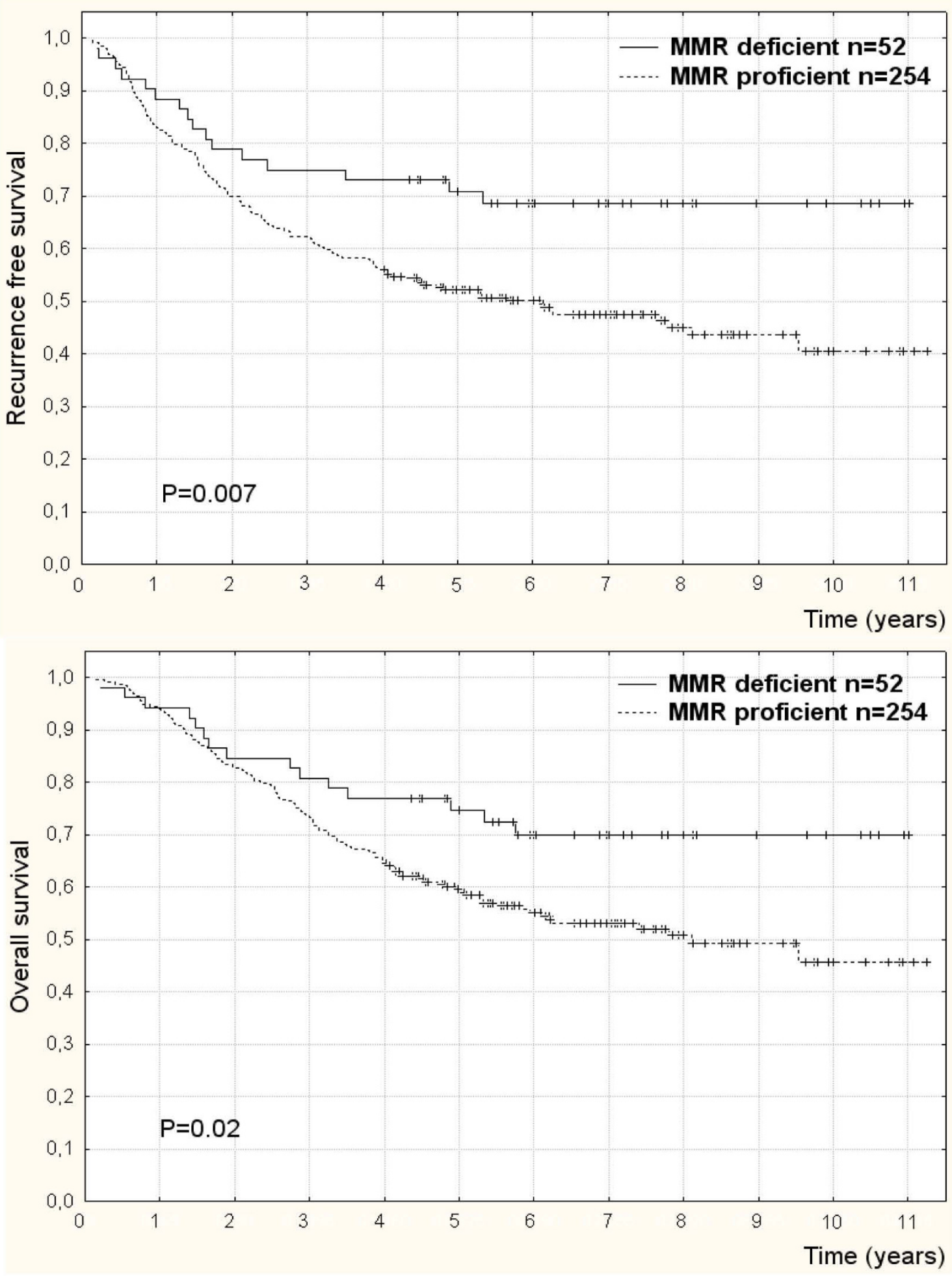

Figure I

Recurrence free survival (a) and overall survival (b) according to mismatch repair deficiency from loss of either hMSH2, hMSH6, or hMLHI in colorectal cancers of patients completely resected and adjuvantly treated with 5-fluorouracil. Censored data $(+)$. 

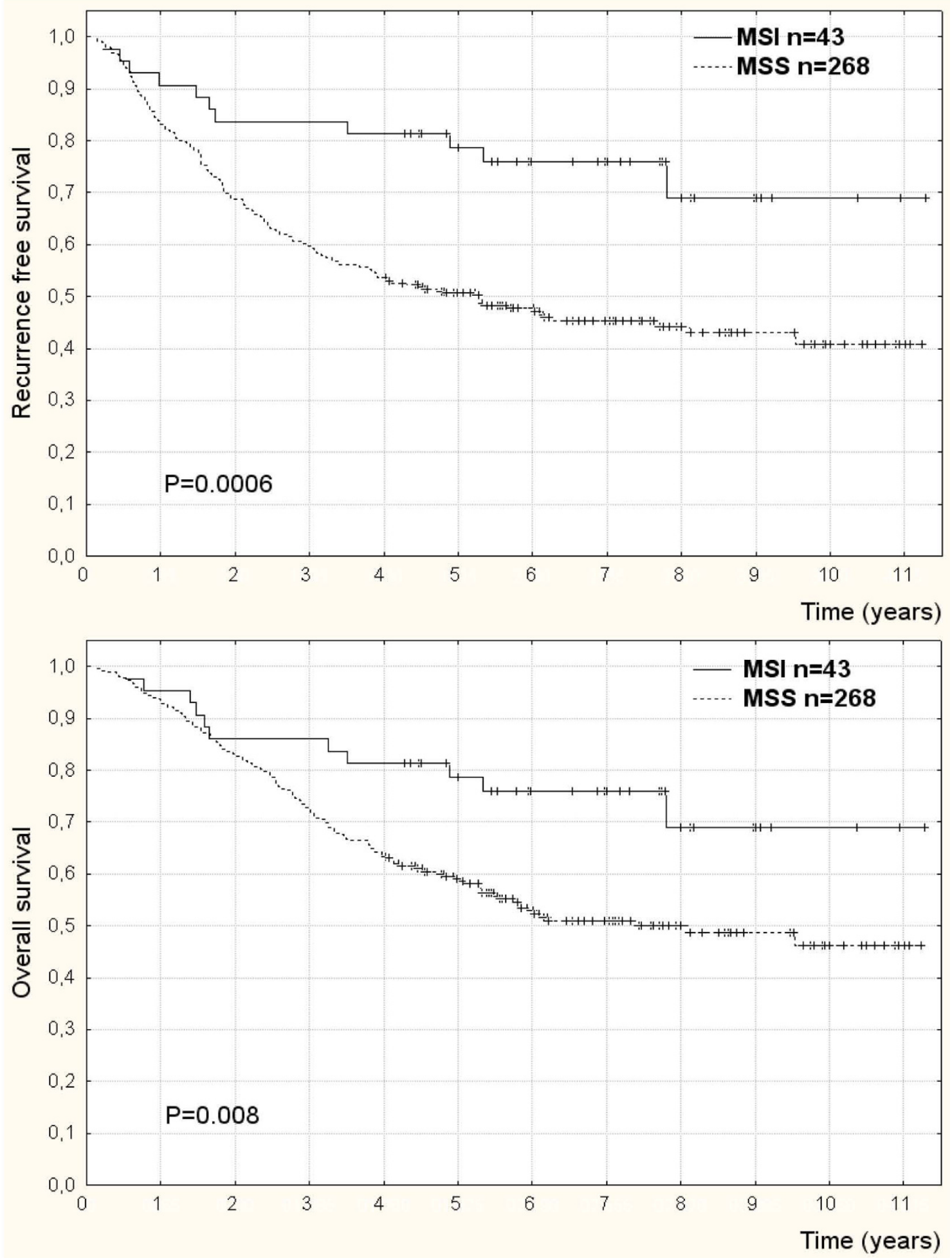

Figure 2

Recurrence free survival (a) and overall survival (b) by instable (MSI) and stable (MSS) microsatellites in tumors of colorectal cancer patients completely resected and adjuvantly treated with chemotherapy. Censored data $(+)$. 

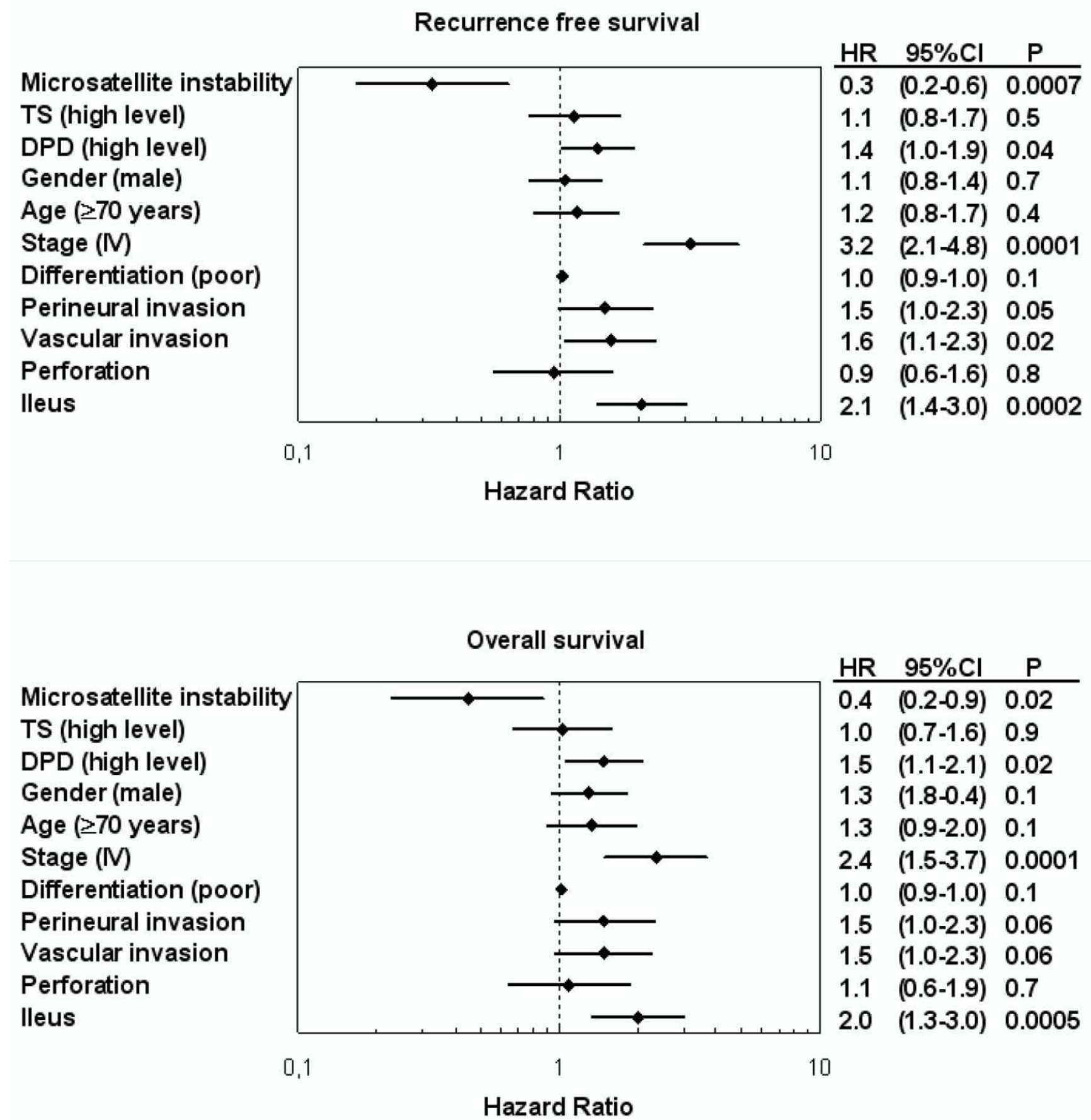

Figure 3

Forest plots displaying multivariate Cox analysis of variables prognostic to recurrence free survival and overall survival following complete resection of colorectal cancer and adjuvant chemotherapy. The prognostic variables included clinicopathological characteristics, tumor microsatellite status, expression of thymidylate synthase (TS) and dihydropyrimidine dehydrogenase (DPD). 
gle microsatellite marker $[38,40]$ whereas others $[5,36,44]$ applied more restricted criteria [24]. Also technical matters regarding immunohistochemical assessment of TS expression may have led to different results. While $24 \%$ of cases in this cohort had high TS score, the proportion in other studies has ranged between $19-77 \%$ of colorectal cancers in the adjuvant setting [45].

As prospective trials usually exclude elderly patients [5], also the age distributions of patient cohorts may have varied between studies. This raises the question whether high TS expression is confined to either inherited or sporadic MSI cancers that usually arise at an average age in the midforties or beyond the age of 70 years, respectively [46]. Difference in TS expression might be of significance to varying outcome of MSI tumors seen in the context of inherited repair deficiency [33].

Significantly higher TS score in tumors deficient of hMLH1 as compared to those deficient of hMSH2 or hMSH6, actually did support the notion that TS expression may vary according to the etiology of mismatch repair deficiency.

Though the pattern of microsatellite instability and resultant influence on gene deregulation may depend on the mechanism of mismatch repair deficiency, no causal connection can be deduced from the high TS expression found in MSI tumors. The fact that microsatellite instability not being involved in recombinant events leading to TS gene variability $[40,43,44]$ suggests that the phenomenon is rather of secondary character. Thus the somewhat paradoxical mucinous histology and poor differentiation of MSI tumors $[38,41]$ have metabolic traits implying higher intensity and diffuse pattern of TS expression [20].

Taken together there are no evidence to suggest direct influence of microsatellite instability on DPD or TS expression, nor that differential expression of these enzymes mediates the features for tumor biology or 5fluorouracil resistance of MSI carcinomas.

The discrepancy in results obtained with the MSI and immunohistochemical methods may have various causes. The subsets analysed with either methods in this study is partly overlapping for technical reasons as indicated in results section. The most significant limitation of immunohistochemistry is the semiquantitative nature of immunostaining and the loss of sensitivity secondary to antigenic alterations caused by fixation procedures. Faint staining may be considered non-specific leading to higher sensitivity and lower specificity for defining MMR deficiency, or vice versa. Moreover a mutant protein product can be expressed and detected by immunohistochemistry. Conversely MMR protein mutations may occur in tumors displaying no MSI. These analytical shortcomings preclude that the methods may unambiguously reflect each other.

\section{Conclusion}

Microsatellite instability due to MMR deficiency is one of the main biomarkers in colorectal cancer, as it not only indicates the pathogenesis, but also provides information on prognosis and prediction of response to chemotherapy. Future investigations into gene targets for microsatellite instability-driven deregulation may clarify the molecular foundation for the distinct clinicopathological characteristics of MSI carcinomas.

\section{Abbreviations}

MSI: Microsatellite instability; MSS: microsatellite stability; MMR: mismatch repair; TS: thymidylate synthase; DPD: dihydropyrimidine dehydrogenase.

\section{Competing interests}

The authors declare that they have no competing interests.

\section{Authors' contributions}

SAJ and JBS conceived and planned the study. SAJ collected and integrated the clinical data. BV collected the tumor specimens from the departments of pathology. BV conducted the immunohistochemical analyses, scoring and interpretations. MK performed the microsatellite analyses, readings and interpretations. SAJ performed data analyses, and made the curve plots and the statistics. SAJ and JBS interpreted the results and SAJ wrote the manuscript draft. All authors critically read through and contributed to the revision of the manuscript draft. All authors approved the final manuscript.

\section{Acknowledgements}

Dr.Masakazu Fukushima (Taiho Pharmaceutical Company, Japan) generously provided DPD antibody. Augustinus Foundation, Merchant M.Brogaard and wife's Foundation, Harboe Foundation, Karen A.Tolstrup Foundation, Dagmar Marshalls Foundation, A.P.Møller Foundation for the Advancement of Medical Science, the Hartmann Brothers Foundation, Director Michael Hermann Nielsen's Foundation, Manufacturer Einar Willumsen Foundation, Merchant Sven Hansen and wife Ina Hansen Foundation, Torben and Alice Frimodt Foundation, Mastersmith Niels Hansen and wife Foundation, Director Werner Richter and wife Foundation and King Christian $X$ Foundation have supported this study.

\section{References}

I. Greenlee RT, Hill-Harmon MB, Murray T, Thun M: Cancer statistics, 200 I. CA Cancer J Clin 200I, 5 I:I5-36.

2. Ribic CM, Sargent DJ, Moore MJ, Thibodeau SN, French AJ, Goldberg RM, Hamilton SR, Laurent-Puig P, Gryfe R, Shepherd LE, Tu D, Redston $M$, Gallinger S: Tumor microsatellite-instability status as a predictor of benefit from fluorouracil-based adjuvant chemotherapy for colon cancer. N Engl J Med 2003, 349:247-257.

3. Liang JT, Huang KC, Cheng AL, Jeng YM, Wu MS, Wang SM: Clinicopathological and molecular biological features of colorectal cancer in patients less than 40 years of age. Br J Surg 2003, 90:205-214. 
4. Elsaleh $\mathrm{H}$, lacopetta $\mathrm{B}$ : Microsatellite instability is a predictive marker for survival benefit from adjuvant chemotherapy in a population-based series of stage III colorectal carcinoma. Clin Colorectal Cancer 200I, I: 104-109.

5. Kim GP, Colangelo LH, Wieand HS, Paik S, Kirsch IR, Wolmark N, Allegra CJ: Prognostic and predictive roles of high-degree microsatellite instability in colon cancer: a National Cancer Institute-National Surgical Adjuvant Breast and Bowel Project Collaborative Study. J Clin Oncol 2007, 25:767-772.

6. Colombino M, Cossu A, Manca A, Dedola MF, Giordano M, Scintu F, Curci A, Avallone A, Comella G, Amoruso M, Margari A, Bonomo GM, Castriota M, Tanda F, Palmieri G: Prevalence and prognostic role of microsatellite instability in patients with rectal carcinoma. Ann Oncol 2002, I 3: I 447-I 453.

7. Aaltonen LA, Peltomaki P, Mecklin JP, Jarvinen $\mathrm{H}$, Jass JR, Green JS, Lynch HT, Watson P, Tallqvist G, Juhola M: Replication errors in benign and malignant tumors from hereditary nonpolyposis colorectal cancer patients. Cancer Res 1994, 54:1645-1648.

8. Prolla TA, Pang Q, Alani E, Kolodner RD, Liskay RM: MLHI, PMSI, and $\mathrm{MSH2}$ interactions during the initiation of DNA mismatch repair in yeast. Science 1994, 265:1091-1093.

9. Lim SB, Jeong SY, Lee MR, Ku JL, Shin YK, Kim WH, Park JG: Prognostic significance of microsatellite instability in sporadic colorectal cancer. Int J Colorectal Dis 2004, 19:533-537.

10. de la Chapelle A: Microsatellite instability. N Engl J Med 2003, 349:209-210.

II. Popat S, Hubner R, Houlston RS: Systematic review of microsatellite instability and colorectal cancer prognosis. J Clin Oncol 2005, 23:609-618

12. Carethers JM, Smith EJ, Behling CA, Nguyen L, Tajima A, Doctolero RT, Cabrera BL, Goel A, Arnold CA, Miyai K, Boland CR: Use of 5 fluorouracil and survival in patients with microsatelliteunstable colorectal cancer. Gastroenterology 2004, I 26:394-40I.

13. Carethers JM, Chauhan DP, Fink D, Nebel S, Bresalier RS, Howell SB, Boland CR: Mismatch repair proficiency and in vitro response to 5-fluorouracil. Gastroenterology 1999, I | 7:|23-13|.

14. Aguiar S Jr, Lopes A, Soares FA, Rossi BM, Ferreira FO, Nakagawa WT, Carvalho AL, David Filho WJ: Prognostic and predictive value of the thymidylate synthase expression in patients with non-metastatic colorectal cancer. Eur J Surg Oncol 2005, 31:863-868.

15. Sugiyama $Y$, Kato T, Nakazato H, Ito K, Mizuno I, Kanemitsu T, Matsumoto K, Yamaguchi A, Nakai K, Inada K, Tatematsu M: Retrospective study on thymidylate synthase as a predictor of outcome and sensitivity to adjuvant chemotherapy in patients with curatively resected colorectal cancer. Anticancer Drugs 2002, 13:931-938.

16. Edler D, Glimelius B, Hallstrom M, Jakobsen A, Johnston PG, Magnusson I, Ragnhammar $\mathrm{P}$, Blomgren $\mathrm{H}$ : Thymidylate synthase expression in colorectal cancer: a prognostic and predictive marker of benefit from adjuvant fluorouracil-based chemotherapy. Clin Oncol 2002, 20:1721-1728.

17. Tomiak A, Vincent M, Earle CC, Johnston PG, Kocha W, Taylor M, Maroun J, Eidus L, Whiston F, Stitt L: Thymidylate synthase expression in stage II and III colon cancer: a retrospective review. Am J Clin Oncol 200I, 24:597-602.

18. Johnston PG, Fisher ER, Rockette HE, Fisher B, Wolmark N, Drake JC, Chabner BA, Allegra CJ: The role of thymidylate synthase expression in prognosis and outcome of adjuvant chemotherapy in patients with rectal cancer. J Clin Oncol 1994, 1 2:2640-2647

19. Tsuji T, Sawai T, Takeshita H, Nakagoe T, Hidaka S, Atsushi N, Yamaguchi H, Yasutake T, Nagayasu T, Tagawa Y: Tumor dihydropyrimidine dehydrogenase in stage II and III colorectal cancer: low level expression is a beneficial marker in oraladjuvant chemotherapy, but is also a predictor for poor prognosis in patients treated with curative surgery alone. Cancer Lett 2004, 204:97-104.

20. Jensen SA, Vainer B, Sorensen JB: The prognostic significance of thymidylate synthase and dihydropyrimidine dehydrogenase in colorectal cancer of $\mathbf{3 0 3}$ patients adjuvantly treated with 5-fluorouracil. Int I Cancer 2007, I 20:694-70I.

21. Ohrling K, Edler D, Hallstrom M, Ragnhammar P, Blomgren $\mathrm{H}$ Detection of Thymidylate Synthase Expression in Lymph Node Metastases of Colorectal Cancer Can Improve the Prognostic Information. J Clin Oncol 2005, 23:5628-5634.
22. Lassmann S, Hennig M, Rosenberg R, Nahrig J, Schreglmann J, Krause F, Poignee-Heger M, Nekarda H, Hofler H, Werner M: Thymidine phosphorylase, dihydropyrimidine dehydrogenase and thymidylate synthase mRNA expression in primary colorectal tumors-correlation to tumor histopathology and clinical follow-up. Int J Colorectal Dis 2005, 21 :238-247.

23. Buhard O, Cattaneo F, Wong YF, Yim SF, Friedman E, Flejou JF, Duva A, Hamelin R: Multipopulation analysis of polymorphisms in five mononucleotide repeats used to determine the microsatellite instability status of human tumors. J Clin Oncol 2006, 24:24I-25I.

24. Umar A, Boland CR, Terdiman JP, Syngal S, de la CA, Ruschoff J, Fishe R, Lindor NM, Burgart LJ, Hamelin R, Hamilton SR, Hiatt RA, Jass J, Lindblom A, Lynch HT, Peltomaki P, Ramsey SD, Rodriguez-Bigas MA, Vasen HF, Hawk ET, Barrett JC, Freedman AN, Srivastava S: Revised Bethesda Guidelines for hereditary nonpolyposis colorectal cancer (Lynch syndrome) and microsatellite instability. J Nat Cancer Inst 2004, 96:26I-268.

25. Suraweera N, Duval A, Reperant M, Vaury C, Furlan D, Leroy K, Seruca R, lacopetta B, Hamelin R: Evaluation of tumor microsatellite instability using five quasimonomorphic mononucleotide repeats and pentaplex PCR. Gastroenterology 2002, I23:|804-|8|I.

26. Barnetson RA, Tenesa A, Farrington SM, Nicholl ID, Cetnarskyj R, Porteous ME, Campbell H, Dunlop MG: Identification and survival of carriers of mutations in DNA mismatch-repair genes in colon cancer. N Engl J Med 2006, 354:275I-2763.

27. Watanabe T, Wu TT, Catalano PJ, Ueki T, Satriano R, Haller DG, Benson $A B$ III, Hamilton SR: Molecular predictors of survival after adjuvant chemotherapy for colon cancer. $N$ Engl J Med 200I, 344: II 96-I206.

28. Hemminki A, Mecklin JP, Jarvinen H, Aaltonen LA, Joensuu H: Microsatellite instability is a favorable prognostic indicator in patients with colorectal cancer receiving chemotherapy. Gastroenterology 2000, I 19:921-928.

29. Barratt PL, Seymour MT, Stenning SP, Georgiades I, Walker C, Birbeck K, Quirke P: DNA markers predicting benefit from adjuvant fluorouracil in patients with colon cancer: a molecular study. Lancet 2002, 360:1381-1391.

30. Elsaleh H, Joseph D, Grieu F, Zeps N, Spry N, lacopetta B: Association of tumour site and sex with survival benefit from adjuvant chemotherapy in colorectal cancer. Lancet 2000 , 355: 1745-1750.

3I. Benatti P, Gafa R, Barana D, Marino M, Scarselli A, Pedroni M, Maestri I, Guerzoni L, Roncucci L, Menigatti M, Roncari B, Maffei S, Rossi G Ponti G, Santini A, Losi L, Di Gregorio C, Oliani C, Ponz dL, Lanza G: Microsatellite instability and colorectal cancer prognosis. Clin Cancer Res 2005, I I:8332-8340.

32. Jover R, Zapater P, Castells A, Llor X, Andreu M, Cubiella J, Pinol V, Xicola RM, Bujanda L, Rene JM, Clofent J, Bessa X, Morillas JD, Nicolas-Perez D, Paya A, Alenda C: Mismatch repair status in the prediction of benefit from adjuvant fluorouracil chemotherapy in colorectal cancer. Gut 2006, 55:848-855

33. de Vos tot Nederveen Cappel WH, Meulenbeld HJ, Kleibeuker JH, Nagengast FM, Menko FH, Griffioen G, Cats A, Morreau H, Gelderblom H, Vasen HF: Survival after adjuvant 5-FU treatment for stage III colon cancer in hereditary nonpolyposis colorectal cancer. Int J Cancer 2004, 109:468-471.

34. Malesci A, Laghi L, Bianchi P, Delconte G, Randolph A, Torri V, Carnaghi C, Doci R, Rosati R, Montorsi M, Roncalli M, Gennari L, Santoro A: Reduced likelihood of metastases in patients with microsatellite-unstable colorectal cancer. Clin Cancer Res 2007 13:3831-3839.

35. Gryfe R, Kim H, Hsieh ET, Aronson MD, Holowaty EJ, Bull SB, Redston $M$, Gallinger S: Tumor microsatellite instability and clinical outcome in young patients with colorectal cancer. $N$ Engl IMed 2000, 342:69-77.

36. Ricciardiello L, Ceccarelli C, Angiolini G, Pariali M, Chieco P, Paterini P, Biasco G, Martinelli GN, Roda E, Bazzoli F: High thymidylate synthase expression in colorectal cancer with microsatellite instability: implications for chemotherapeutic strategies. Clin Cancer Res 2005, I I:4234-4240.

37. Okon K, Klimkowska A, Wojcik P, Osuch C, Papla B, Stachura J: High thymidylate synthase expression is typical for sporadic MSIH colorectal carcinoma. Pol J Pathol 2006, 57:29-33. 
38. Sinicrope FA, Rego RL, Halling KC, Foster NR, Sargent DJ, La Plant B, French AJ, Allegra CJ, Laurie JA, Goldberg RM, Witzig TE, Thibodeau $\mathrm{SN}$ : Thymidylate synthase expression in colon carcinomas with microsatellite instability. Clin Cancer Res 2006, I 2:2738-2744.

39. Michael-Robinson JM, Reid LE, Purdie DM, Biemer-Huttmann AE, Walsh MD, Pandeya N, Simms LA, Young JP, Leggett BA, Jass JR, Radford-Smith GL: Proliferation, apoptosis, and survival in highlevel microsatellite instability sporadic colorectal cancer. Clin Cancer Res 200I, 7:2347-2356.

40. Curtin K, Ulrich CM, Samowitz WS, Bigler J, Caan B, Potter JD, Slattery ML: Thymidylate synthase polymorphisms and colon cancer: associations with tumor stage, tumor characteristics and survival. Int J Cancer 2007, I 20:2226-2232.

41. Popat S, Wort R, Houlston RS: Inter-relationship between microsatellite instability, thymidylate synthase expression, and p53 status in colorectal cancer: implications for chemoresistance. BMC Cancer 2006, 6:150.

42. Calascibetta A, Cabibi D, Martorana A, Sanguedolce G, Rausa L, Feo $S$, Dardanoni G, Sanguedolce R: Thymidylate synthase gene promoter polymorphisms are associated with TSmRNA expressions but not with microsatellite instability in colorectal cancer. Anticancer Res 2004, 24:3875-3880.

43. Merkelbach-Bruse S, Hans V, Mathiak M, Sanguedolce R, Alessandro R, Ruschoff J, Buttner R, Houshdaran F, Gullotti L: Associations between polymorphisms in the thymidylate synthase gene, the expression of thymidylate synthase mRNA and the microsatellite instability phenotype of colorectal cancer. Oncol Rep 2004, I I:839-843.

44. Agostini M, Pulciarelli S, Bertorelle R, Calandra P, Villani F, Lise M, Nitti D: Genetic heterogeneity of variable number tandem repeats in thymidylate synthase gene in colorectal cancer patients. Int J Biol Markers 2004, 19:332-336.

45. Popat S, Matakidou A, Houlston RS: Thymidylate synthase expression and prognosis in colorectal cancer: a systematic review and meta-analysis. J Clin Oncol 2004, 22:529-536.

46. Herman JG, Umar A, Polyak K, Graff JR, Ahuja N, Issa JP, Markowitz S, Willson JK, Hamilton SR, Kinzler KW, Kane MF, Kolodner RD, Vogelstein B, Kunkel TA, Baylin SB: Incidence and functional consequences of $\mathrm{hMLHI}$ promoter hypermethylation in colorectal carcinoma. Proc Natl Acad Sci USA 1998, 95:6870-6875.

\section{Pre-publication history}

The pre-publication history for this paper can be accessed here:

http://www.biomedcentral.com/1471-2407/9/25/prepub
Publish with Bio Med Central and every scientist can read your work free of charge

"BioMed Central will be the most significant development for disseminating the results of biomedical research in our lifetime. "

Sir Paul Nurse, Cancer Research UK

Your research papers will be:

- available free of charge to the entire biomedical community

- peer reviewed and published immediately upon acceptance

- cited in PubMed and archived on PubMed Central

- yours - you keep the copyright
BioMedcentral 